\title{
Tissue-specific gene activation by MyoD: determination of specificity by cis-acting repression elements
}

\author{
Harold Weintraub, ${ }^{1}$ Tom Genetta, ${ }^{2}$ and Tom Kadesch ${ }^{2}$ \\ ${ }^{1}$ Hutchinson Cancer Center, Howard Hughes Medical Institute, Seattle, Washington 98104 USA; ${ }^{2}$ Department of Genetics \\ and Howard Hughes Medical Institute, University of Pennsylvania School of Medicine, Philadelphia, Pennsylvania \\ 19104-6145 USA
}

MyoD is a muscle-specific transcriptional activator; E12 is a B-cell activator. An IgH enhancer is activated almost 100-fold by E12 but not at all by MyoD; an MCK enhancer is activated almost 1000-fold by MyoD and not at all by E12. MyoD and E12 are both basic helix-loop-helix proteins that bind to similar E-box sequences (CANNTG); the IgH enhancer contains the same $E$ boxes as the MCK enhancer, yet each retains exclusive specificity for either E12 or MyoD, respectively. We show that the IgH enhancer contains a cis-acting negative element that is directed at MyoD, but not at E12. This repression requires the $\mu \mathrm{E} 5 \mathrm{E}$ box within the IgH enhancer; however, the specificity for repression, as opposed to activation, is associated with 2 bp flanking each side of the $\mu E 5 \mathrm{E}$ box. The target for repression of MyoD in the IgH enhancer is the bHLH region of MyoD. Our results suggest that MyoD only activates myogenic genes because nonmuscle enhancers that contain $E$ boxes also contain negative elements that prevent MyoD activity.

[Key Words: MyoD; transcriptional repression; $\mathrm{E}$ box; IgH enhancer]

Received June 23, 1994; revised version accepted August 5, 1994.

Basic helix-loop-helix (bHLH) proteins are used frequently for specifying terminally differentiated cell types - the MyoD family, for skeletal muscle (for review, see Emerson 1990; Olson 1990; Buckingham 1992; Weintraub 1993); the achaete-scute family, for nerve (for review, see Ghysen et al. 1993; Jan and Jan 1993); the SCL gene, for hematopoiesis (Aplan et al. 1992); and the differentially spliced products of the E2A gene (E12, E47, E2-5), for B-cell differentiation (Murre et al. 1989a; Kadesch 1992, 1993). Many bHLH proteins form heterodimers with members of the E2 family of genes (E2A, E2-2, and HEB) and bind to a simple enhancer box (E-box) DNA sequence (CANNTG) to activate tissue-specific transcription (Murre et al. 1989a, b; Blackwell and Weintraub 1990; Lassar et al. 1991; Ruezinsky et al. 1991). A major paradox is that in vitro, a given cell type-specific bHLH protein can often bind to $\mathrm{E}$ boxes present in tissuespecific enhancers of many different cell types. Why then, for example, does MyoD not activate E-box-containing immunoglobulin genes in muscle cells and why do the E2 gene products not activate E-box-containing myogenic genes in B cells?

Here, we show that the immunoglobulin heavy chain (IgH) enhancer discriminates between MyoD and E2 through a mechanism involving negative control. Specifically, a minimal IgH enhancer contains three $\mathrm{E}$ boxes but is not activated by MyoD. Mutations within and adjacent to one $\mathrm{E}$ box, $\mu \mathrm{E} 5$, allow MyoD to activate this enhancer. Thus, MyoD is a muscle-specific activator for two reasons: First, because it is expressed only in muscle; and second, when expressed in muscle, MyoD is prevented from activating $\mathrm{E}$ boxes in at least one nonmuscle enhancer, the IgH enhancer, because this enhancer has evolved to contain repressing elements directed at MyoD and not at E12.

\section{Results}

\section{MyoD fails to activate the IgH enhancer}

Figure 1A shows that in transient transfection assays using $3 \mathrm{~T} 3$ cells, MyoD activates the intact $3.3-\mathrm{kb}$ muscle-specific MCK enhancer (Jaynes et al. 1988), but E12 (or the differentially spliced product, E2-5) does not; in contrast, E12 activates the 62-bp B-cell-specific IgH enhancer (Henthorn et al. 1990; Ruezinsky et al. 1991), whereas MyoD does not. Both E boxes in the MCK enhancer are contained in the IgH enhancer: $\mu \mathrm{E} 5$ is identical to the MCK R site, and $\mu \mathrm{E} 3$, to the MCK L site. $\mu \mathrm{E} 2$ is not present in the MCK enhancer; however, it is not needed for E12 activation or for MyoD repression (Fig. 1B). As controls, oligomerized R sites (4R) or L sites (4L) from the MCK enhancer are activated by either MyoD or E12 (Fig. 1B). 
Weintraub et al.

A

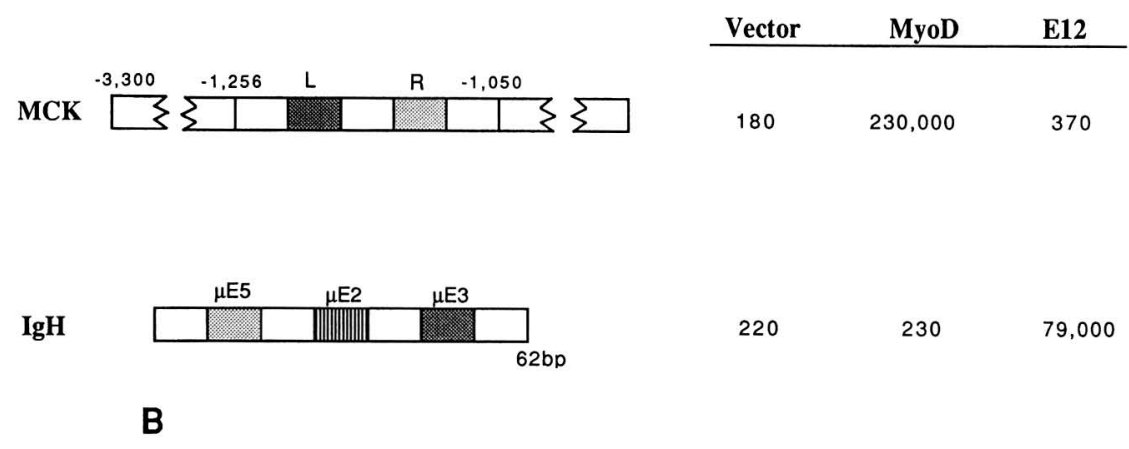

Figure 1. Specificity of MyoD for the MCK enhancer and E 12 for the IgH enhancer. (A) NIH-3T3 cells were cotransfected with either a MyoD or E12 expression vector and the entire MCK enhancer $(-3300\}$ MCK-CAT (Jaynes et al. 1988), or the IgH enhancer $(\mu E 3,2,5)$ as described previously (Kadesch et al. 1986). In a typical experiment, cells were plated at about onefourth confluency and transfected using calcium phosphate the next day. Usually, the template was at $8 \mu \mathrm{g}$ and the activator at $6 \mu \mathrm{g}$ per plate. Cells were rinsed the next day and grown for 1 day in DME with $10 \%$ calf serum and then 2 days in DME with 10 $\mu \mathrm{g} / \mathrm{ml}$ of transferrin and $10 \mu \mathrm{g} / \mathrm{ml}$ of insulin. The $\operatorname{IgH}$ enhancer is oligomerized $(4 \times)$ and drives a single TATA box CAT construct (Ruezinsky et al. 1991). All of the experiments in Figures 1-5 have been repeated 3-10 times each, with the same results. Entries are averages normalized to the highest value in each series. $(B) \mathrm{A}$ cisacting negative control element $(\mu \mathrm{E} 5)$ directed at repression of $\mathrm{MyoD}$ in the $\operatorname{lgH}$ enhancer. Point mutations (Ruezinsky et al. 1991) in the various $E$ boxes of the IgH enhancer (indicated by the vertical black bars/ were assayed with the indicated transactivators as described in $A$.

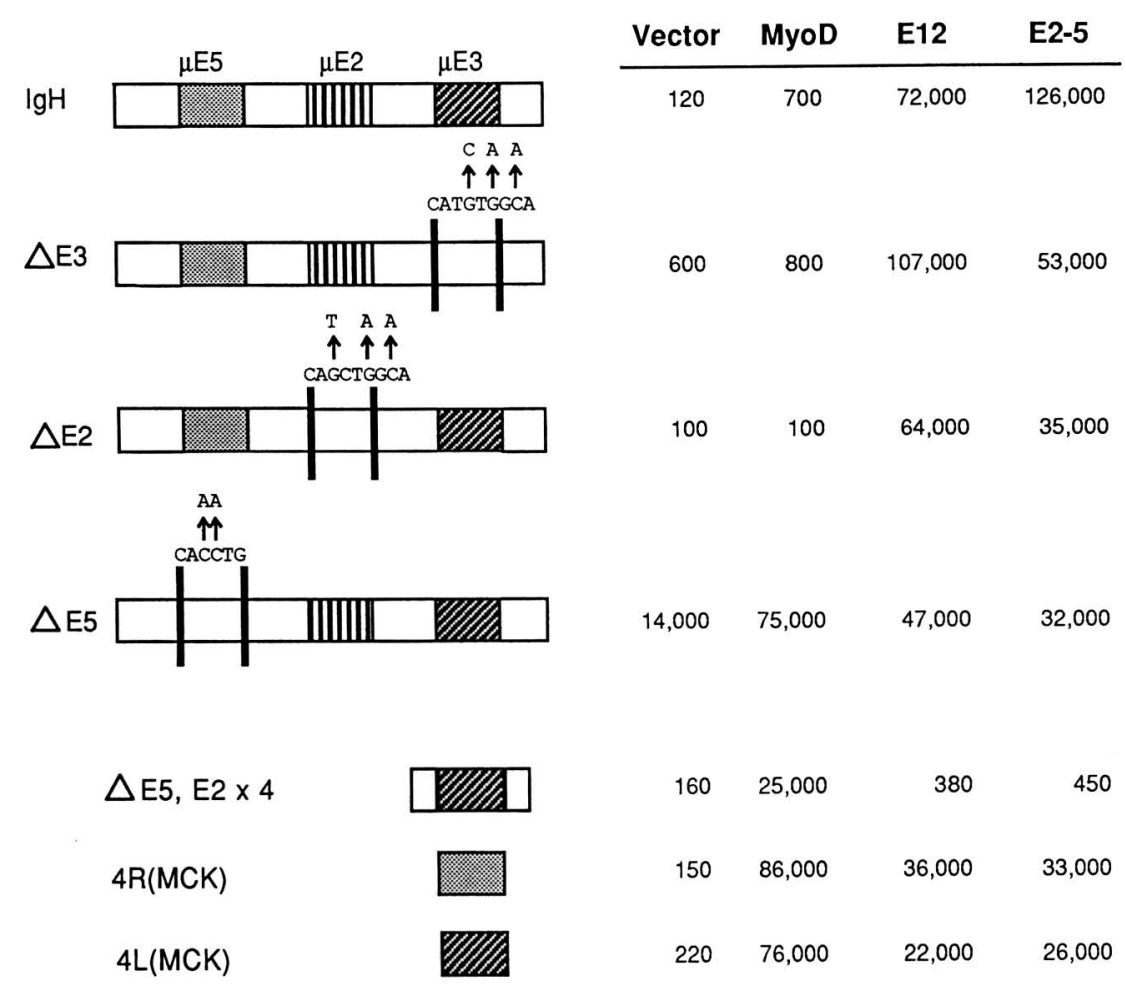

$\mu E 5$ determines a repression mechanism for $M y o D$ but not E12

To investigate why MyoD fails to activate the IgH enhancer, we initially mutated each of the $E$ boxes in the $\mu E 5,2,3$ enhancer (Fig. 1B). Mutation of $\mu E 5(\Delta \mu E 5)$ resulted in a higher basal level of activity (expression vector alone); $\Delta \mu E 5$ also retained the ability to be activated by E12 but lost the capacity to repress MyoD. The increased basal level of activity seen with $\Delta \mu E 5$ suggests that $\mu \mathrm{E} 5$ is associated with a cis-acting negative activity directed at one or more endogenous transcription factors present in most cells; for example, USF, TFE3, Myc,
Max, etc. (Ruezinsky et al. 1991). As shown below (Fig. 2), the complication associated with a high basal level of activity in the $\Delta \mu \mathrm{E} 5$ mutant can be eliminated by using a series of templates missing $\mu \mathrm{E} 2$. In contrast to the results with $\Delta \mu \mathrm{E} 5$, mutation of $\mu \mathrm{E} 3$ or $\mu \mathrm{E} 2$ resulted in templates that retained both MyoD repression and the specificity for E12 activation. These results suggest that $\mu \mathrm{E} 5$ is a cis-acting negative element that prevents $\mathrm{MyoD}$ activation but does not prevent E12 activation of the $\operatorname{IgH}$ enhancer.

To characterize further the MyoD inhibitory element $(\mu \mathrm{E} 5)$ in the IgH enhancer, we used a series of simplified wild-type and mutant E-box enhancers coupled to $\mu \mathrm{E} 3$ 
$\mu \mathbf{E} 5+\mu \mathbf{E} 3:$

GATCTCCOCT CAGGTGI TCCAGATTGGATCTGGT CATGTG_CAAGGCTATTTGGT agGGGajGTCCACAAGGTCTAACCTAGACCA GTACACEGTTCCGATAAACCAGATC

$\kappa E 2+\mu E 3:$

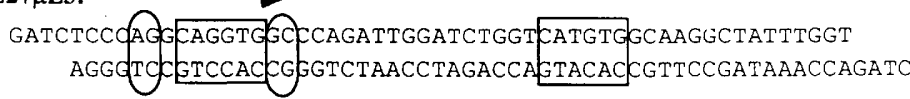

$\mu E 5+$ mutant $\mu E 2+\mu E 3:$ GATCTAGAACACCTG OAGATCTAGAAGGATCTGG TATGTG_CAAGGCTATTTGGT ATCLIGTGGACSCGTAGATCTTCCTAGACCA GTACACETTCCGATAAACCAGATC

mutant $-\mu \mathrm{E} 5+\mu \mathrm{E} 3$ : GATCTCTGGCACGTCAGCCATCCTCGGGATCTGGT CATGTGECAAGGCTATTTGGT AgACOGTGCAGICGGTAGGAGCCCTACACCA GTACACEGTTCCGATAAACCAGATC
240 800 12,000 2,500

Vector MyoD E12 E12(AT)

290

$400 \quad 22,000$

3,000

150 83,000

18,000

24,000

360

30,0000

2,000

12,000

Figure 2. Mapping of $\mu$ E5 repression to 4 bp flanking the 6-bp E box. The indicated enhancers were oligomerized $(4 \times)$ and linked to the same TATA box CAT construct (Genetta et al. 1994) used and assayed as in Fig. 1. Note that in contrast to the templates used in Fig. 1, these constructs have been simplified as much as possible so that $\mu \mathrm{E} 2$ is not present. E12 (AT) is E12 containing the basic region residues of $\mathrm{MyoD}\left(\mathrm{A}_{114} \mathrm{~T}_{115}\right)$ substituted into the corresponding region of E12 for NN (Davis and Weintraub 1992).

(i.e., missing $\mu E 2$ ) and oligomerized fourfold (Fig. 2). Comparing the two sequences $[(\mu \mathrm{E} 5+\mu \mathrm{E} 3)$ vs. $(\kappa \mathrm{E} 2+\mu \mathrm{E} 3)]$ reveals that MyoD-directed inhibitory activity is correlated with $4 \mathrm{bp}$ (circled) that flank the $\mu \mathrm{E}-5 \mathrm{E}$ box. An additional comparison of the two plasmids $[\langle\mu \mathrm{E} 5$ $+\mu \mathrm{E} 3$ ) vs. ( $\mu \mathrm{E} 5$ plus mutant $\mu \mathrm{E} 2$ plus $\mu \mathrm{E} 3$ )] suggests that the $\mu \mathrm{E} 5$ negative element (containing the core 6-bp E box plus $3 \mathrm{bp}$ upstream and $3 \mathrm{bp}$ downstream/ can function when inverted and when placed almost one-half of a helical turn away from $\mu E 3$. The same features of $\mathrm{MyOD}$ repression (Fig. 1 and 2) were also obtained using Myf-5 and myogenin, and identical results are also obtained after transfection of the various $\mathrm{IgH}$ mutants into $\mathrm{C} 2$ myoblasts, which provide $\mathrm{MyoD}$ and myogenin endogenously (data not shown). Our main conclusion is that a very few base pairs that flank the canonical $6 \mathrm{bp} \mu \mathrm{E} 5$ element determine whether or not $\mu \mathrm{E} 5$ is positive or negative for MyoD activation. These flanking base pairs have little effect on the ability of E12 to activate. In addition, the integrity of the $\mu \mathrm{E} 5 \mathrm{E}$-box core sequence (CACCTG) is also needed for MyoD repression (Fig. 1B), because a mutation to (CAAATG) prevents repression. Recently, Simon and Burden (1993) have described an E box in the $\delta$-acetylcholine receptor gene that is responsible for negative control of this muscle gene in fibroblasts. Because their sequence differs from $\mu \mathrm{E} 5$ in the flanking base pairs, it may interact with a different repressor.

The marked differences in expression between the various E-box-binding site combinations shown in Figure 2 are not easily explainable in terms of simple differences in binding affinities. Using MyoD-E47 heterodimers made in Escherichia coli, no differences in binding were observed between the two extreme sequences ( $\kappa E 2-\mu E 3)$ and $(\mu \mathrm{E} 5-\mu \mathrm{E} 3)$, either as pure proteins or in cell extracts (data not shown). In addition, a comparison of the capacity of MyoD-E47 heterodimers versus E47 homodimers to displace a possible zinc finger repressor, Zeb (see belowl, have also led to no differences manifest by the two sequences.

A striking result suggesting that the $\mu \mathrm{E} 5$ repressor can work at some distance and in an entirely different context is shown in Figure 3. The IgH enhancer was inserted either upstream or downstream from a 48-bp minimal MyoD-dependent, MCK enhancer, spanning the $\mathrm{R}$ and $\mathrm{L}$ $E$ boxes. In both cases, MyoD-dependent activation of the chimeric enhancer was markedly inhibited while E12-dependent activation was, if anything, enhanced. In contrast to the full MCK enhancer (Fig. 1), the minimal MCK enhancer described in Figure 3 is activated by E12 - suggesting that cis-acting negative elements (located either upstream or downstream of the $\mathrm{R}$ and $\mathrm{L}$ E boxes) control E12 negatively but not MyoD at the full MCK enhancer. Identification of the sequence responsible for this putative E12-directed repression is currently in progress.

To test whether the $\mu \mathrm{E} 5$ site is inhibitory to MyoD in the context of the intact IgH enhancer (i.e., a larger enhancer element that is not oligomerized), a MyoD expression vector was cotransfected into $3 \mathrm{~T} 3$ cells with the intact enhancer or the same enhancer mutated in just the $\mu \mathrm{E} 5$ site (Fig. 4). As a result of the $\mu \mathrm{E} 5$ mutation, 
Figure 3. Repression of $\mathrm{MyoD}$ at the MCK enhancer mediated by insertion of a neighboring IgH enhancer. An MCK expression vector containing only $48 \mathrm{bp}$ of the MyoD-dependent enhancer (Bengal et al. 1994) was cut at a single site with $\mathrm{XbaI}$ or HindIII, and the oligomerized $(4 \times) \mathrm{IgH}$ enhancer shown in Fig. 1 was cloned into these sites to give templates with the IgH enhancer either upstream (HindIII) or downstream $(\mathrm{XbaI})$ of the MCK enhancer. Transfections into 3T3 cells with either MyoD or E12 were as described in Fig. 1.

\section{MCK}

IgH
MCK
IgH

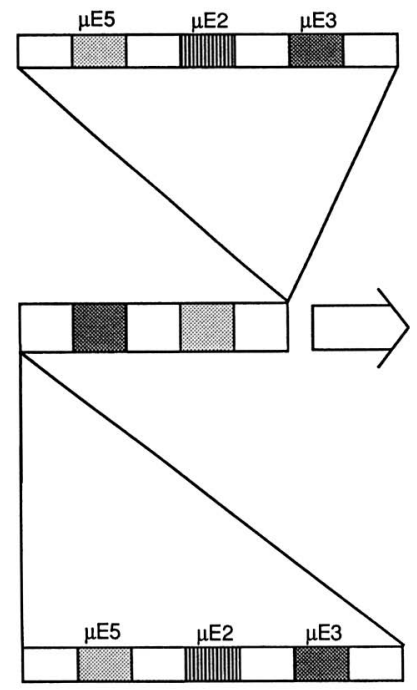

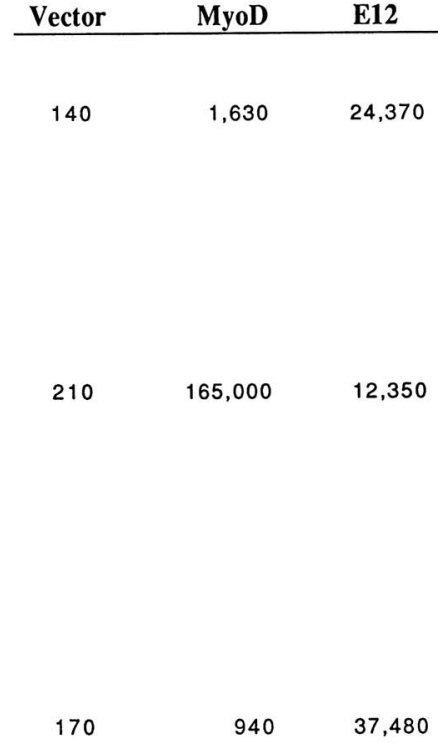

transcription increases $10-30$-fold. Similar results are obtained using C2 myoblasts (data not shown). These results again indicate that $\mu \mathrm{E} 5$ mediates cis-acting negative control on adjacent sites potentially activatable by MyoD.

\section{$\mu E 5$ repression is targeted to the MyoD bHLH}

To identify the domain in MyoD that is the target for $\mu E 5$-mediated repression, we analyzed deletions of MyoD that are still capable of activation (Tapscott et al. 1988), as well as chimeric proteins between MyoD and E12 (see Davis and Weintraub 1992). Removal of either the amino terminus of MyoD $(\Delta 3-56)$ or the carboxyl terminus (167-318) or the Cys-His-rich region (63-99) had little effect on MyoD activation of the MCK enhancer and repression still occurred on the $\mu E 5,2,3$ enhancer (Fig. 4B). By elimination, this suggests that the target for repression by $\mu \mathrm{E} 5$ is the bHLH region of $\mathrm{MyoD}$. This is supported by the observation that the inability of MyoD to activate the IgH enhancer can be overcome by replacing MyoD bJH1 with E12 bJH1 (Fig. 4B). Figure 4B also shows that $\mathrm{MyoD}(\mathrm{E} 12 \mathrm{bJH})$ fails to activate the MCK enhancer. This suggests that as is the case for the IgH enhancer, the repression system for $\mathrm{MCK}$ is, at least in part, directed against the bJH1 region, in this instance, of E12. The discrimination between MyoD and E12 is subtle. A mutant version of E12, in which 2-amino-acid

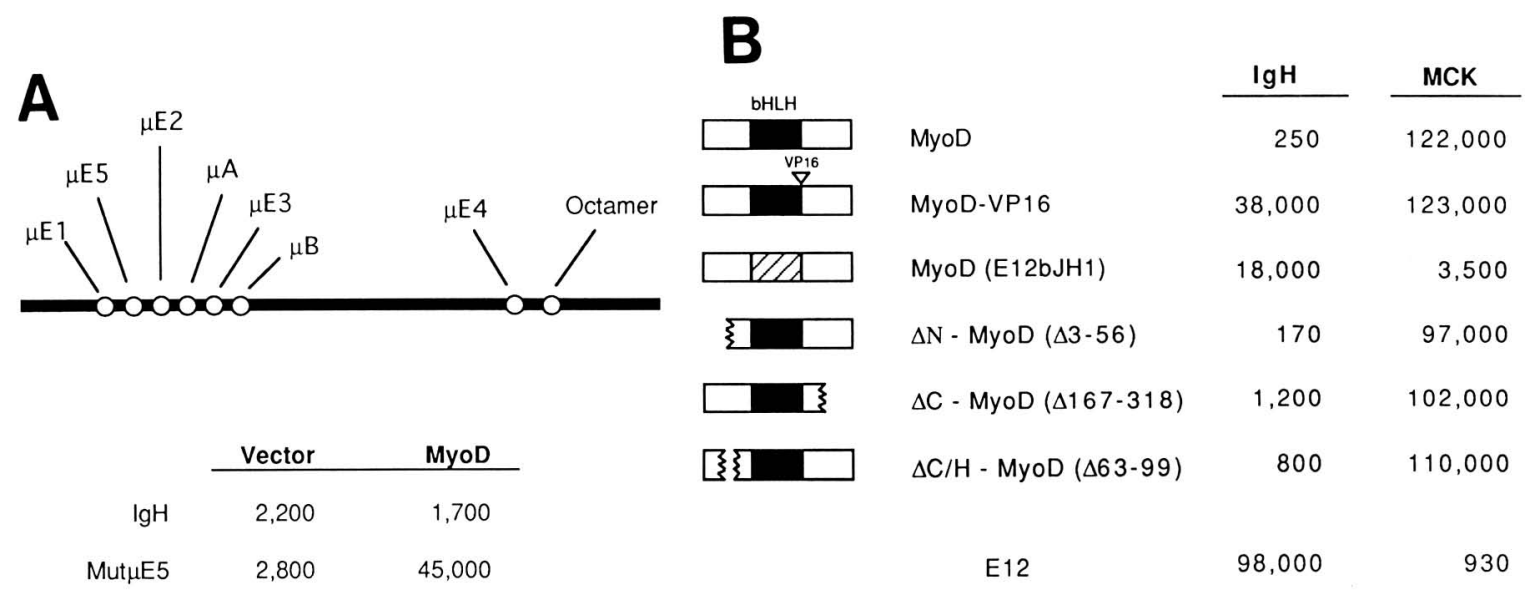

Figure 4. Repression of $\mathrm{MyoD}$ at the $\mathrm{IgH}$ locus is directed at the bHLH domain. $(A)$ Repression of MyoD at the intact IgH enhancer. A single IgH enhancer [339 bp HinfI-EcoRI (Kadesch et al. 1986)] was linked to TK-CAT and assayed for activation by MyoD in 3T3 cells (Fig. 1). A variant (Mut $\mu$ E5) was also assayed (Kadesch et al. 1986). (B) Localization of $\mu E 5$-mediated repression of MyoD to the MyoD bHLH region. The oligomerized IgH enhancer, $\mu E 5,2,3$, or the $3300 \mathrm{MCK}$ enhancer were assayed as in Fig. 1 with various MyoD deletions (Tapscott et al. 1988), various MyoD and E12 chimeric proteins (Davis and Weintraub 1992), or MyoD-VP16 (Weintraub et al. 1991). 
residues present in the basic region of MyoD (Ala-114 and Thr-115) are swapped into the corresponding positions in E12 (Davis and Weintraub 1992), is a good activator of $(\kappa \mathrm{E} 2+\mu \mathrm{E} 3\}$, but a poor activator of $(\mu \mathrm{E} 5+\mu \mathrm{E} 3)$ (Fig. 2B). We interpret this to mean that as the basic region of E12 becomes more MyoD-like, the $\mu \mathrm{E} 5$ repressor becomes a more effective inhibitor of E12. In support of this, like MyoD and in contrast to E12, E12 (AT) can activate a reporter driven by only the $\mu \mathrm{E} 3$ sequence (Fig. 2; mutant $\mu \mathrm{E} 5+\mu \mathrm{E} 3$ ).

\section{MyoD-VP16 activates the IgH enhancer}

Repression of $\mathrm{MyoD}$ at the $\mathrm{IgH}$ locus may function by "silencing" already bound MyoD. Some evidence for this comes from the observation that addition of the VP16 activation domain to MyoD (MyoD-VP16) activates the IgH enhancer (Fig. 4B). One interpretation of these results is that MyoD can bind to the IgH enhancer but it is normally silenced by the $\mu \mathrm{E} 5$ repressor; addition of the VP16 activation domain bypasses this silencing. Other interpretations are also possible. For example, perhaps the presence of the VP16 activation domain allows MyoD-VP16 to displace the $\mu$ E5 repressor.

\section{E12 bypasses the $\mu E 5$ repressor}

E12 fails to activate (mutant E5 $+\mu \mathrm{E} 3$ ) (Fig. 2). This is not surprising as E12 binds poorly to the $\mu \mathrm{E} 3$ sequence because the $T$ immediately upstream of the $E$ box is incompatible with binding (Blackwell and Weintraub 1990). However, E12 can activate the wild-type $(\mu \mathrm{E} 5+\mu \mathrm{E} 3)$ construct, suggesting that the $\mu \mathrm{E} 5$ site is used for E12 activation in this template. These results suggest that E12 can bypass (or displace) the $\mu \mathrm{E} 5$ repressor responsible for MyoD repression (see also Ruezinsky et al. 1991; Genetta et al. 1994). In contrast, MyoD can activate (mutant $\mu \mathrm{E} 5+\mu \mathrm{E} 3$ ) but cannot activate $(\mu \mathrm{E} 5+\mu \mathrm{E} 3)$, suggesting that $\mathrm{MyoD}$, although capable of binding to and activating through each of the core, 6-bp $\mathrm{E}$ boxes associated with $\mu \mathrm{E} 5, \mu \mathrm{E} 2$, and $\mu \mathrm{E} 3$ (data not shown), cannot bypass or displace the repression mechanism associated with the IgH $\mu$ E5 E-box and flanking sequences.

\section{E12 can derepress $\mu E 5$, allowing $M y o D$ to activate}

To test the idea that E12, but not MyoD, can displace or otherwise obviate the $\mu E 5$ repressor, we attempted to show synergy between E12 and MyoD at the IgH enhancer. We use an E12 derivative (E12 $\Delta N$ ) lacking the amino-terminal activation domain. This fails to activate the IgH enhancer (Table 1). Similarly, MyoD fails to activate. However, the two together give a high level of activity. In contrast, E $12 \Delta \mathrm{N}$ is a weak inhibitor of $\mathrm{MyoD}$ using either the (KE2 +E3) template (Fig. 2) or the $4 \mathrm{R}$ template (Fig. 1B). These results are consistent with the notion that $\mathrm{E} 12 \Delta \mathrm{N}$ can displace the $\mu \mathrm{E} 5$ repressor of MyoD and, when cotransfected with MyoD, allow MyoD to activate the IgH enhancer. The level of synergy
Table 1. Activation of $M y O D$ at the IgH enhancer by $a$ truncated E12

\begin{tabular}{lrrr}
\hline & \multicolumn{1}{c}{$4 \mathrm{R}$} & $\mathrm{kE} 2+\mathrm{E} 3$ & \multicolumn{1}{c}{$\mathrm{IgH}$} \\
\hline Vector & 180 & 240 & 195 \\
E12 $\Delta \mathrm{N}$ & 280 & 350 & 470 \\
MyoD & 98,000 & 110,000 & 160 \\
MyoD + E12 $\mathrm{N}$ & 47,000 & 41,000 & 24,000 \\
E12 & 74,000 & 93,000 & 110,000 \\
E12 + E12 $\Delta N$ & 64,000 & 71,000 & 48,000 \\
\hline
\end{tabular}

$\mathrm{E} 12 \Delta \mathrm{N}$ is missing the amino-terminal activation domain and is described in Davis and Weintraub (1992). All other procedures are described in Figs. 1 and 2 . Templates were at $5 \mu \mathrm{g}$ per dish, activators were at $7 \mu \mathrm{g}$ per dish, and E12 were at $7 \mu \mathrm{g}$ per dish. Values are the average of three separate transfections.

is restricted by a competing reaction in which $\mathrm{E} 12 \Delta \mathrm{N}$ also inhibits $\mathrm{MyoD}$, presumably because it is a weaker activation partner for MyoD than full-length E12. Thus, it seems that $\mathrm{E} 12 \Delta \mathrm{N}$ can displace or otherwise bypass the inhibitory activity of the $\mu \mathrm{E} 5$ repressor on MyoD, but $\mathrm{MyoD}$ is not equipped to do this. An alternative explanation is that cotransfection of $E 12 \Delta \mathrm{N}$ increases the concentration of a MyoD-E12 $\Delta \mathrm{N}$ heterodimer and that this species can bind more efficiently and activate because of its increased concentration. To test this, increasing concentrations of MyoD vector were transfected with saturating levels of E12 and the IgH expression vector. Addition of $\mathrm{MyoD}$ actually reduced activation by E12 (data not shown), suggesting that with more $\mathrm{MyoD}$, the levels of E12 homodimers decrease because of formation of MyoD-E12 heterodimers, and the MyoD-E12 heterodimer is inhibited at the IgH locus even though it is presumably at a much higher concentration.

\section{$M y o D$ is unlikely to be the $\mu E 5$ repressor}

The experiments presented thus far do not rule out the possibility that MyoD itself, when bound to the $\mu \mathrm{E} 5 \mathrm{se}$ quence, acts as an inhibitor. To test this possibility we assayed a number of IgH derivative reporters (similar to those shown in Fig. 2) for those that would retain MyoD repression of an adjacent $\mu \mathrm{E} 3$ site but lose in vitro MyoD binding to $\mu \mathrm{E} 5$. Figure 5 shows the sequence of the parent $\mu E 5$ site together with two additional templates. The (Mef-1 $+\mu$ E3) template contains a sequence (Mef-1) that can bind $\mathrm{MyoD}$, yet it fails to inhibit activation, presumably because of an A-T change at position +5 ; thus, MyoD binding per se to a site adjacent to $\mu \mathrm{E} 3$ is not sufficient to cause repression. In addition, the (mutantMef-1 $+\mu E 3$ | template has a sequence that fails to bind MyoD, but still retains repression of MyoD on the neighboring $\mu \mathrm{E} 3$ site. Thus, for these two templates, binding by MyoD and repression of MyoD can be dissociated, and consequently, we believe it unlikely that MyoD is the $\mu E 5$ repressor; however, these results cannot rule out a more complex model wherein MyoD in conjunction 
Weintraub et al.

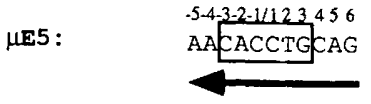

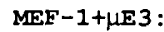

GATCTCCCCAA CACCTGTGCCTGAGGGATCTGGT FATGTGFCAAGGCTATTTGGT AGGGGT TIGTGGACGACGGACTCCCTAGACCA GTACAOCGTTCCGATAAACCAGATC

\begin{tabular}{l}
$\begin{array}{l}\text { MyoD } \\
\text { Binding to } \\
\text { Left Site }\end{array}$ \\
Myod \\
Activation \\
\hline
\end{tabular}

$++$

84,000

mutant-MEF-1+ $\mathbf{E} 3$ :

GATCTCCCCAACACGGTAACCCTGAGGGATCTGGTCATGTG SAAGGCTATTTGGT

AGGGGTT GTGCCATTGGGACTCCCTAGACCAGTACACEGTTCCGATAAACCAGATC

250

Figure 5. Sequences that lose MyoD binding but retain repression. The $\mu \mathrm{E} 5$ repression sequences as deduced from Fig. 2 are given at the top. The two indicated templates are described in Genetta et al. (1994) and were oligomerized (4X) and linked to a TATA-CAT vector. MyoD binding refers to binding to the Mef-1 site or mutant Mef-1 site and is described in Blackwell and Weintraub (1990). Transfections were done as described in Fig. 2.

with another protein (i.e., a corepressor) acts as an inhibitor associated with $\mu \mathrm{E} 5$.

\section{$\mu E 5$ is not a general repressor}

To examine whether the $\mu \mathrm{E} 5$ repressor could inhibit other trans-activators besides MyoD, we cloned five Gal4 DNA-binding sites adjacent to an intact IgH enhancer (Fig. 6). When challenged with either Gal-Ela or Gal-VP16 chimeric activators, no inhibition was observed even though this construct preserved its property of inhibiting MyoD while allowing E12 activation. Thus, the $\mu \mathrm{E} 5$ repressor seems to be rather specific in that it cannot inhibit an adjacent Gal-VP16 or Gal-Ela fusion protein. When challenged with Gal MyoD, there is a reproducible three- to fivefold inhibition of Gal-MyoD compared with Gal-VP16 or Gal-Ela. Although the degree of inhibition is significant, it is also much less than that of MyoD.

\section{Discussion}

cis-Acting negative sequences contribute to the tissue specificity of bHLH proteins

Our results demonstrate that the complex IgH enhancer has evolved in such a way that it contains negative control sequences that inhibit MyoD but do not inhibit E12. Cis-acting inhibitory sequences are common control elements found in association with a large number of genes. What is unusual to the present situation is $(1)$ the degree of specificity-the $\mu \mathrm{E} 5$ repression system is almost absolute for inhibiting MyoD as compared with the related bHLH protein, E12; (2) the functional similarity of the two activators-substitution of only 3 amino acid residues from MyoD into E12 converts E12 into a myogenic protein (Davis and Weintraub 1992) and substitution of only 2 amino acids from the MyoD basic region into the corresponding positions in E12 converts E12 into a protein more like MyoD when assayed at the IgH

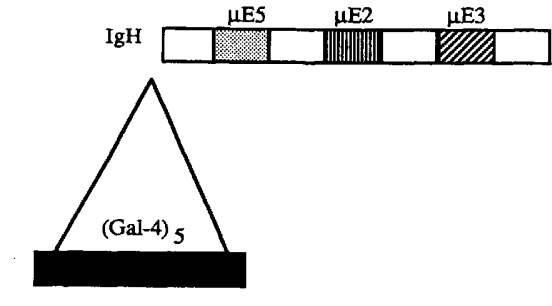

$(\mathrm{Gal}-4)_{5}$ \begin{tabular}{llllll} 
Gal-424 Gal-VP16 & Gal-Ela & Gal-MyoD & MyoD & E12 \\
\hline
\end{tabular}

340

108,000

99,000

9,000

1,000

84,000
102,000

35,000

740

680

Figure 6. Specificity of $\mu \mathrm{E} 5$ repressor. (Gal4) $)_{5}$ was inserted into the unique BamHI site of the IgH enhancer plasmid. Gal chimeric proteins are described in Weintraub et al. (1990). Gal-VP16, and Gal-E1 a contain the Gal4 DNA-binding domain fused to the activation domains of VP16, E1a, and MyoD, respectively. Data are from transfections into C2 myoblasts. Gal424 encodes the Gal4 DNA-binding domain. 
locus (Fig. 2); (3) the fact that the "target" for repression on MyoD (the bJHl region) is also the DNA-binding domain as well as an important component of the transcriptional activation process (Davis et al. 1990); and (4) the fact that only very few base pairs flanking $\mu \mathrm{E} 5$ determine whether it is an inhibitor or activator sequence for MyoD. An analysis of the MCK enhancer similarly suggests that cis-acting negative sequences inhibit the activity of E12 but fail to inhibit MyoD (cf. Figs. 1A and 3 ). As is the case for MyoD and the $\mu E 5$ repressor, the cis-acting negative sequences in the MCK enhancer also seem to be directed, at least in part, at the bHLH region of E12 [Fig. 4B; MyoD (E12bJH1)]. Cis-acting negative elements such as the $\mu \mathrm{E} 5$ repressor are likely to contribute to the exquisite tissue specificity of E-box-binding proteins. Together with our previous results showing that only 3 amino acid residues from MyoD can convert E12 to a myogenic protein [E12 $(\mathrm{A}, \mathrm{T}$, and $\mathrm{K})]$, the present studies raise the possibility that this myogenic conversion occurs not because $\mathrm{E} 12(\mathrm{~A}, \mathrm{~T}$, and $\mathrm{K})$ binds a positive coactivator, but because E12 (A, T, and $\mathrm{K}$ ) avoids negative regulation normally directed at a crucial endogenous myogenic control gene, for example, at endogenous MyoD or myogenin.

\section{The mechanism of $\mu E 5$ silencing}

Our experiments with the $\mu \mathrm{E} 5$ silencer raise two overlapping issues. One is the ability of this silencer to specifically inhibit MyoD bound to rather distantly located sites. The second is the capacity of E12, but not MyoD, to either displace or otherwise inactivate or bypass the $\mu E 5$ silencer. Previous work also identified $\mu E 5$ as an inhibitory element for the constitutively expressed bHLH zipper protein TFE3 (Ruezinsky et al. 1991; Kadesch 1992, 1993; Genetta et al. 1994). The identity of the $\mu$ E5 repressor(s)-either for TFE3 or for MyoD-is not known nor is the repression mechanism; however, a zinc finger protein (ZEB) that binds to $\mu \mathrm{E} 5$ recently has been cloned (Genetta et al. 1994) and attempts to determine whether Zeb is the MyoD specific $\mu \mathrm{E} 5$ repressor are in progress. Becaue the DNA-binding domains of Zeb can bind in vitro equally well to both KE2 and $\mu \mathrm{E} 5$ (Genetta et al. 1994), it is at first difficult to see how Zeb could be the $\mu \mathrm{E} 5$ MyoD repressor; however, other factors could contribute in the cell. Related work (Gonzalez-Crespo and Levine 1993) has shown that the zinc finger repressor, snail, can compete for binding with the bHLH protein activator, twist, and that depending on relative concentrations, an on/off threshold of activation can be seen in vivo. In contrast, the $\mu E 5$ repressor can act from a distinct site at some distance and is demonstrated to distinguish between different bHLH proteins.

As our assays are largely in both $3 \mathrm{~T} 3$ and C2 cells, we presume that the negative factors associated with $\mu \mathrm{E} 5$ are not muscle specific. Given the way this system of negative regulation seems to have evolved, where the specificity for inhibition is directed at target domains in tissue-specific bHLH activator proteins, there need not necessarily be any tissue specificity at all to the expres- sion of the negative regulator(s). It will be interesting to know whether the $\mu \mathrm{E} 5$ silencer can also inhibit the nerve cell-specific achaete-scute bHLH protein, or whether another cis-acting repression system elsewhere in the $\mathrm{IgH}$ locus is responsible for supposed repression directed at achaete-scute. Less specific mechanisms for repression, for example, those mediated by histones, should also be considered. Our experiments also fail to rule out a mechanism wherein the $\mu \mathrm{E} 5$ sequences force MyoD itself into a "negative conformation" and, hence, MyoD may be the $\mu$ E5 repressor (e.g., see Saver and Jäckle 1993). Some evidence against this possibility is presented in Figure 6, where we describe one site that fails to bind to MyoD but maintains repression and another site that maintains MyoD binding but fails to mediate repression; however, these results do not rule out a more complex model where a coinhibitor functions in conjunction with $\mathrm{MyoD}$, both for binding and for repression.

It is also not known whether in myoblasts the same MyoD-directed $\mu \mathrm{E} 5$ repressor that functions at the $\mathrm{IgH}$ locus is used to repress the potential activity of MyoD at other nonmuscle, E-box-containing tissue-specific enhancers. Similarly, in nonmuscle cell types (e.g., B cells) that use different bHLH proteins (e.g., E12), it is not known whether the same $\mu \mathrm{E} 5$ repressor described here is used to repress the activity of myogenic genes (e.g., $\mathrm{MCK}$.

One mechanistic model that can explain our data is the following: The $\mu E 5$ silencer inhibits MyoD bound to $\mu \mathrm{E} 3$ by targeting its bHLH domain. E12 escapes this repression, in part because it can bind to $\mu \mathrm{E} 5$ and displace or inactivate the silencer bound to $\mu \mathrm{E} 5$. How E12, but not $\mathrm{MyoD}$ would do this is not clear. The bHLH region of MyoD is not only required for DNA binding, but it is also involved in subsequent transcriptional activation because positive control mutations (e.g., at Ala-114 in the basic region/ bind normally to DNA but fail to activate transcription (Davis et al. 1990; Bengal et al. 1994; $\mathrm{Ma}$ et al. 1994). There is also evidence that positive control may be mediated through a cofactor that interacts with the bHLH region of MyoD and is absent in rhabdomyosarcoma muscle tumor cells (Tapscott et al. 1993). The present study extends the involvement of the bHLH region to include not only DNA binding and transcriptional activation, but silencing as well. It also raises the possibility that the MyoD positive control mutants fail to activate transcription because they gain the activity of interacting with a MyoD-specific inhibitor, such as the $\mu E 5$ repressor. This is somewhat less likely as there are many different types of amino acid substitutions that give rise to the positive control phenotype.

\section{Why negative control?}

The question arises why the system of tissue-specific bHLH proteins (MyoD, achaete-scute, and SCL) did not evolve so that each member binds a unique target DNA sequence. c-Myc is known to also bind quite well to several noncanonical sequences (Blackwell et al. 1993; 
Ma et al. 1993) and the Drosophila bHLH protein, Enhancer of split, binds the non-E box sequence CACNAG (Tietze et al. 1992). Thus, some bHLH proteins can bind to non-E box DNA sequences. One explanation is that there is something very fundamental and unchangeable about the mechanism of activation by these bHLH proteins and this requires the same basic region that also determines DNA-binding specificity. As discussed above, there is now a large body of evidence that the basic region of MyoD not only mediates sequence-specific DNA binding but also an additional step in subsequent transcriptional activation (Tapscott $1988^{;}$Davis et al. 1990; Davis and Weintraub 1992; Bengal et al. 1994). This activation process may be too complex to tolerate alterations in the basic region that would have to coevolve with different and diverging DNA-binding sites. Contributing to the necessity of keeping binding sites constant may be the pressure to keep E12 as a partner for each of the tissue-specific bHLH proteins. It has been argued that this allows the cell to make mutually exclusive developmental commitments (Weintraub 1993). Finally, conservation of a consensus binding site can also be explained if all tissue-specific bHLH proteins activate a common set of downstream genes (in addition to a unique set of cell type-specific genes) for each to orchestrate its unique cell-specific program. Thus, rather than change the primordial network of proteins that interact with the basic region, perhaps the alternate solution-to derive cis-acting bHLH specific negative control-was more expedient.

\section{Materials and methods}

Plasmids

IgH enhancer-containing plasmids and mutant derivatives have been described previously (Henthorn et al. 1990; Ruezinsky et al. 1991; Genetta et al. 1994). Briefly, $\Delta \mu E 5$ changes CACCTG to CAAATG; $\Delta \mu \mathrm{E} 2$ changes CAGCTGGC to CATCTAGA; and $\Delta \mu \mathrm{E} 3$ changes CATGTGGC to CATCTAGA. The MCK enhancer (Jaynes et al. 1988) and MyoD and E12 expression vectors and mutant derivatives (Davis and Weintraub 1992) have also been described. The chimeric IgH-MCK enhancer (Fig. 3) was made by cutting a TK-CAT plasmid that contains 48 bp encompassing the $R$ and $L$ sites of the MCK enhancer (Bengal et al. 1994) either upstream (HindIII) or downstream (XbaI) of the enhancer. This was ligated with the oligomerized IgH enhancer (Fig. 1) released by BamHI and BgIII digestion.

\section{Cells and transfections}

NIH-3T3 cells and C2 myoblasts were maintained at low density in Dulbecco's modified Eagle medium (DME) plus $10 \%$ calf serum (GIBCO). Cells were transfected with calcium phosphate precipitates, and the next day, rinsed with phosphate buffered saline and incubated for 1 day in DME plus $10 \%$ calf serum. MyoD was then activated by serum removal and growth in DME plus $10 \mu \mathrm{g} / \mathrm{ml}$ of insulin and $10 \mu \mathrm{g} / \mathrm{ml}$ of transferrin. Cells were collected and assayed for CAT expression (Weintraub et al. 1991).

\section{Acknowledgments}

This work was supported by Howard Hughes Medical Institute and the National Institutes of Health. We would like to thank our colleagues for their comments.

The publication costs of this article were defrayed in part by payment of page charges. This article must therefore be hereby marked "advertisement" in accordance with 18 USC section 1734 solely to indicate this fact.

\section{References}

Aplan, P.D., K. Nakahara, S.H. Orkin, and I.R. Kirsch. 1992. The SCL gene product: A positive regulator of erythroid differentiation. EMBO I. 11: 4073-4081.

Bengal, E., O. Flores, P.N. Rangarajan, A. Chen, H. Weintraub, and I. Verma. 1994. Positive control mutations in the MyoD basic region fail to show cooperative DNA binding and transcriptional activation in vitro. Proc. Natl. Acad. Sci. 91: $6221-6225$.

Blackwell, T.K. and H. Weintraub. 1990. Differences and similarities in DNA-binding preferences of MyoD and E2A protein complexes revealed by binding site selection. Science 250: 1104-1110.

Blackwell, T.K., J. Huang, A. Ma, L. Kretzner, F.W. Alt, R.N. Eisenman, and $\mathrm{H}$. Weintraub. 1993. Binding of myc proteins to canonical and noncanonical DNA sequences. Mol. Cell. Biol. 13: 5216-5224.

Buckingham, M. 1992. Making muscle in mammals. Trends Genet. 8: 144-149.

Davis, R.L. and H. Weintraub. 1992. Acquisition of myogenic specificity by replacement of three amino acid residues from MyoD into E12. Science 256: 1027-1030.

Davis, R.L., P.F. Cheng, A.B. Lassar, and H. Weintraub. 1990. The MyoD DNA-binding domain contains a recognition code for muscle-specific gene activation. Cell 60: 733-746.

Emerson, C.P. 1990. Myogenesis and developmental control genes. Curr. Opin. Cell Biol. 2: 1065-1075.

Genetta, T., D. Ruezinsky, and T. Kadesch. 1994. Displacement of an E-box binding repressor by BHLH proteins: implications for B-cell specificity of the IgH enhancer. Mol. Cell. Biol. (in press)

Ghysen, A., C. Dambly-Chaudiere, L.Y. Jan, and Y.N. Jan. 1993. Cell interactions and gene interactions in peripheral neurogenesis. Genes \& Dev. 7: 723-733.

Gonzalez-Crespo, S. and M. Levine. 1993. Interactions between dorsal and helix-loop-helix proteins initiate the differentiation of the embryonic mesoderm and neuroectoderm in Drosophila. Genes \& Dev. 7: 1703-1713.

Henthorn, P., M. Kiledjian, and T. Kadesch. 1990. Two distinct transcription factors that bind the immunoglobulin enhancer microE5/kappa 2 motif. Science 247: 467-470.

Jan, Y.N. and L.Y. Jan. 1993. HLH proteins, fly neurogenesis, and vertebrate myogenesis. Cell 75: 827-830.

Jaynes, J.B., J.E. Johnson, J.N. Buskin, C.L. Gartside, and S.D. Hauschka. 1988. The muscle creatine kinase gene is regulated by multiple upstream elements, including a musclespecific enhancer. Mol. Cell. Biol. 8: 62-70.

Kadesch, T. 1992. Helix-hoop-helix proteins in the regulation of immunoglobulin gene transcription. Immunol. Today 13: 31-36.

1993. Consequences of heteromeric interactions among helix-hoop-helix proteins. Cell Growth \& Differ. 4: 49-55.

Kadesch, T., P. Zervas, and D. Ruezinsky. 1986. Functional analysis of the murine IgH enhancer: Evidence for negative control of cell-type specificity. Nucleic Acids Res. 14: 8209 8221.

Lassar, A.B., R.L. Davis, W.E. Wright, T. Kadesch, C. Murre, A. 
Voronova, D. Baltimore, and H. Weintraub. 1991. Functional activity of myogenic $\mathrm{HLH}$ proteins requires hetero-oligomerization with E12/E47-like proteins in vivo. Cell 66: 305315.

Ma, P., M. Rould, H. Weintraub, and C. Pabo. 1994. Crystal Structure of MyoD bHLH domain bound to DNA: New perspectives on DNA recognition and transcriptional activation. Cell 77: 451-459.

Murre, C., P.S. McCaw, and D. Baltimore. 1989a. A new DNA binding and dimerization motif in immunoglobulin enhancer binding, daughterless, MyoD, and myc proteins. Cell 56: 777-783.

Murre, C., P.S. McCaw, H. Vaessin, M. Caudy, L.Y. Jan, Y.N. Jan, C.V. Cabrera, J.N. Buskin, S.D. Hauschka, and A.B. Lassar. 1989b. Interactions between heterologous helix-loop-helix proteins generate complexes that bind specifically to a common DNA sequence. Cell 58: 537-544.

Olson, E. 1990. A gene with homology to the myc similarity region of MyoDl is expressed during myogenesis and is sufficient to activate the muscle differentiation program. Genes \& Dev. 4: 1454-1461.

Ruezinsky, D., H. Beckmann, and T. Kadesch. 1991. Modulation of the IgH enhancer's cell type specificity through a genetic switch. Genes \& Dev. 5: 29-37.

Saver, F. and H. Jäckle. 1993. Dimerization and the control of transcription by Krüppel. Nature 364: 454-456.

Simon, A.M. and S.J. Burden. 1993. An E box mediates activation and repression of the acetylcholine receptor-subunit gene during myogenesis. Mol. Cell. Biol. 13: 5133-5140.

Tapscott, S.J., R.L. Davis, M.J. Thayer, P.F. Cheng, H. Weintraub, and A.B. Lassar. 1988. MyoD1: A nuclear phosphoprotein requiring a myc homology region to convert fibroblasts to myoblasts. Science 242: 405-411.

Tapscott, S.J., H. Weintraub, and M.J. Thayer. 1993. Deficiency in rhabdomyosarcomas of a factor required for $\mathrm{MyoD}$ activity and myogenesis. Science 259: 1450-1453.

Tietze, K., W. Oellers, and E. Knust. 1992. En Spl. D and its use in the study of domains of HLH proteins. Proc. Natl. Acad. Sci. 89: 6152-6156.

Weintraub, H. 1993. The MyoD family and myogenesis: Redundancy, networks, and thresholds. Cell 75: 1-20.

Weintraub, H., V.J. Dwarki, I. Verma, R. Davis, S. Hollenberg, L. Snider, A. Lassar, and S.J. Tapscott. 1991. Muscle-specific transcriptional activation by MyoD. Genes \& Dev. 5: 13771386. 


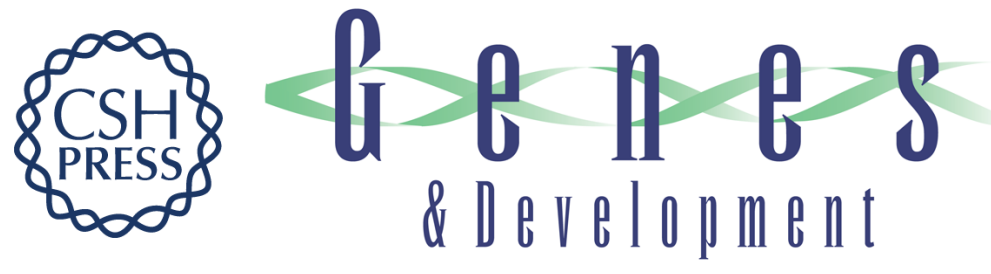

\section{Tissue-specific gene activation by MyoD: determination of specificity by cis-acting repression elements.}

$\mathrm{H}$ Weintraub, T Genetta and T Kadesch

Genes Dev. 1994, 8:

Access the most recent version at doi:10.1101/gad.8.18.2203

References This article cites 29 articles, 15 of which can be accessed free at:

http://genesdev.cshlp.org/content/8/18/2203.full.html\#ref-list-1

License

Email Alerting

Service

Receive free email alerts when new articles cite this article - sign up in the box at the top right corner of the article or click here.

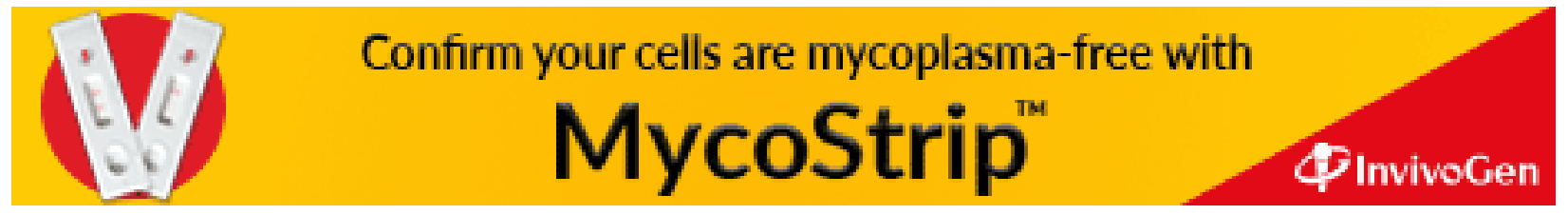

